\title{
An Investigation into the Performance Viability of Recycled Polyester (R-PET) from Virgin Polyester (V-PET)
}

\author{
Hayley McCullough and Danmei Sun* \\ Heriot Watt University, UK
}

*Corresponding author: Danmei Sun, School of Textiles and Design, Heriot Watt University, UK.

Received Date: April 03, 2019

Published Date: May 10, 2019

\begin{abstract}
The environmental impact of plastics has been made increasing concerns in recent years. Post-consumer plastic bottles created an environmental crisis. Polyester is a very versatile fibre material that has been widely used in the textile and fashion industry. However recycled polyester (R-PET) is not yet widely available at a commercial mass-market scale. Also, there is limited academic literature available on the performance characteristics of R-PET in textile form. This study attempts to compile a rounded evaluation of R-PET textiles derived from post-consumer plastic bottles, based on some objective tests related mainly to fabric mechanical properties. Tested samples are from two equivalent fabrics that were developed in this study - one is made of R-PET and the other the virginal polyester (V-PET). R-PET fabric showed very positive results in the tensile strength, abrasion resistance that provided promising potential to be used as a new feedstock for technical textiles, as well as fashion clothing. This will reduce waste to landfill or oceans. It can also reduce the use of new V-PET made of crude oils and reduce pollution and environmental impact.
\end{abstract}

Keywords: Recycled polyester; Strength; Flexibility; Abrasion resistance; Formability

\section{Introduction}

Many sources [1,2], reported that 8 million tonnes as the most accurate figure of plastic waste enters oceans each year. In the UK alone, a Mintel Market Sizes Report [3] demonstrates a market volume of 3.117 billion liters in bottled water for 2016. This data represents only a segment of total plastic bottle consumption figure for the UK, as it excludes figures from carbonated soft drinks, sports drinks and energy drinks (these categories are not broken down to distinguish sales of cans from PET bottles). According to a Guardian report [4], a million plastic bottles are bought around the world every minute and the number will jump another $20 \%$ by 2021, creating an environmental crisis and some campaigners predict will be as serious as climate change. Figure 1 shows an example of a waste plastic bottle centre. The severe quantities of many thermoplastic polymeric materials such as polyethylene terephthalate (PET) is needed to be recycled and reused with increased environmental pollution [5,6]. Recycled polyester (R-PET), derived from polyethylene terephthalate (PET), has been paid great attention and is argued to pose a solution to the high impact fibres which the industry relies on such as polyester and cotton with $55 \%$ and $27 \%$ respective market share as of 2015 [7].

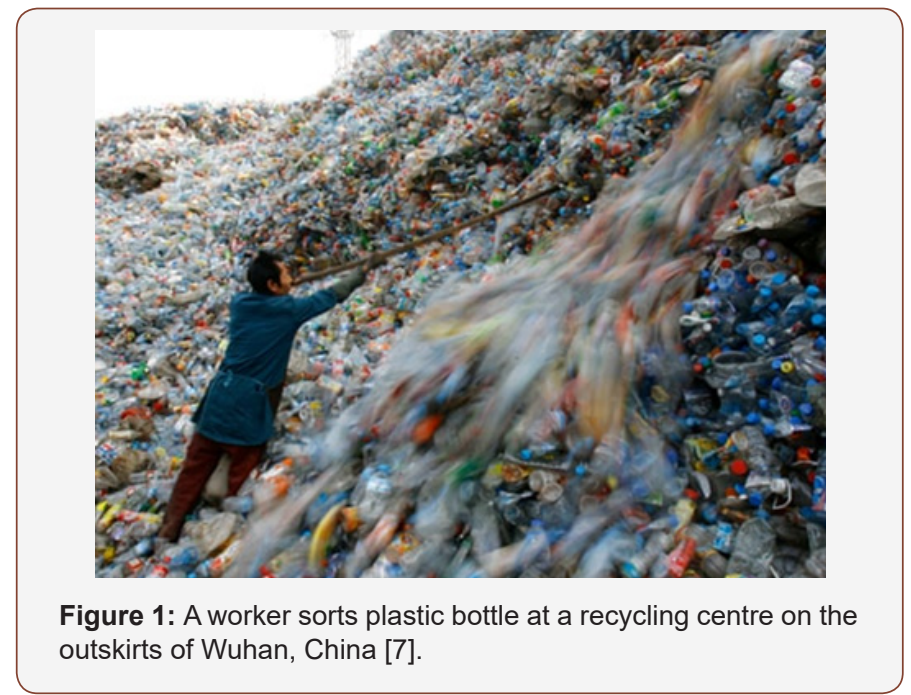

Research work has been done with recycling of thermoplastic PET. The recycling process is mainly subdivided into two categories, physical process via thermal palletization and extrusion process and chemical process involving techniques and processes to make PET decomposition into depolymerized oligomers $[8,9]$. 
The chemical properties of R-PET in comparison to V-PET were studied by Awaji and Pavel [10]. The effect of different methods for formulation and compounding of R-PET on the polymer chains and thermal profile was discussed. Furthermore, Naguib and Zhang reported how to use waste PET in obtaining new environmentally friendly polymeric material utilizing a natural material oleic acid [11]. They claimed a type of new cost-effective ecological R-PET was developed using PET waste bottles. The R-PET polymer was tested of thermal behaviour, hardness, curing mechanism. Furthermore, the thermal behavior studied by DSC/TGA indicated the change in the thermal decomposition phases in addition to some improved thermal stability achieved for the R-PET compared to V-PET. The X-ray diffraction of PET has been studied; it has been found that the esterification reaction for PET created polyester chains with more disordered/amorphous structure. The diffraction change from V-PET to R-PET supports to assure the occurrence of the esterification reaction. The diffraction peaks indicate the polyester phase but with more amorphous character with R-PET [11].

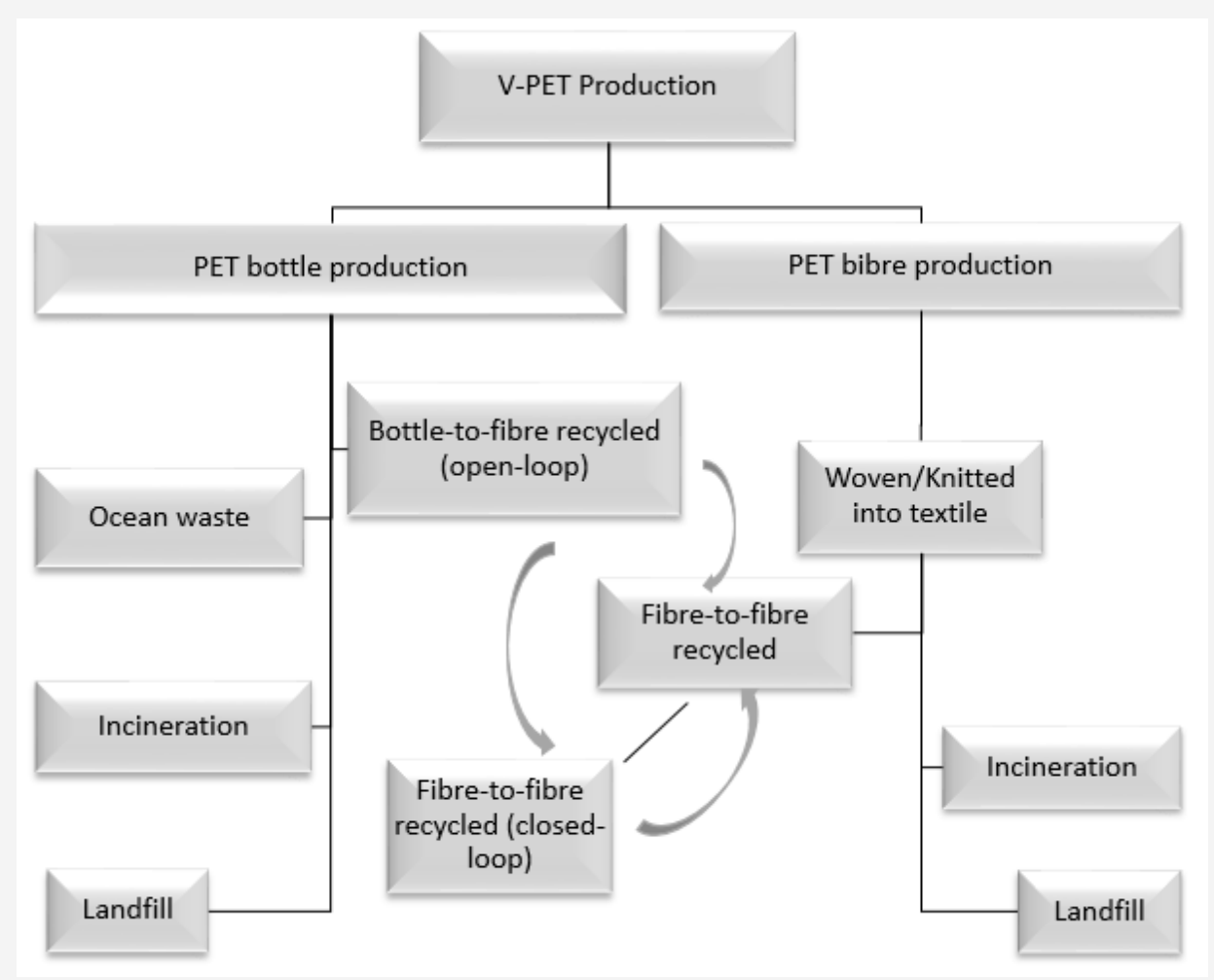

Figure 2: Simplification of life-cycle [12].

R-PET has not yet been made widely available at a commercial, particularly in the mass market level. PET remains the most used fibre in the fashion and textile industry due to its many advantages including its cost-effective aspect in comparison to many other fibres. The life-cycle of the polymer also poses interesting question as it is widely used in disposable products such as soft drinks bottles. With the demanding question of ocean pollution and lack of resources pressing the textile industry for alternative raw materials, there is no doubt that R-PET can offer an idealistic, and also two-pronged solution which can not only reduce waste but also the environmental impact caused in the production of new raw materials. The benefits have been praised by many researchers and questions therefore the potential limitations of this R-PET fibre in textile use which, along with low oil prices, may be withholding the growth of its share in the textiles market as compared to V-PET [3]. Figure 2 shows the life cycles of PET.

Through researching the market, it was found there is a lack of fashion brands using R-PET in their products. Most existing R-PET products are as stand-alone items in novelty range basis. R-PET has not become a common textile product, despite the extensive academic research carried out since the past decade. Most studies were concerned with R-PET's performance in low-value commodities such as cement, or for thermal and sound insulation. Few firms such as TEJIN - a Japanese company, claimed that their R-PET fibre quality is equivalent to that of PET freshly produced from petroleum, through their developed techniques to separate and eliminate additives and colorants not only from PET bottles but also from other PET products and purifies the material to an extent $[12,13]$.

Although PET is the most used plastic fibre that already subjected for recycling; however, there are concerns that the recycling process may lower some of its properties, e.g. mechanical strength etc. [14]. Telli and Babaarslan fulfilled an academic gap in research, confirming stiffness in objective tests as an R-PET weakness, discovering also that bending rigidity increased after washing. More research work needs to be done in the property examination of the R-PET. This study aims to evaluate some physical and mechanical properties of fabrics made of R-PET and make comparisons to an equivalent fabric made of V-PET. 


\section{Material and Methodology}

\section{Materials}

R-PET and V-PET yarns with the same linear density were supplied by Morssinkhof Sustainable Products and Hailide Fibers Europe respectively. Two fabrics were designed and manufactured using a weaving loom at the School of Textiles and Design, HeriotWatt University. The detailed fabric specifications are presented in Table 1.

Table 1: Specifications of R-PET and V-PET fabrics.

\begin{tabular}{|c|c|c|c|}
\hline Fabric Characteristic & $\begin{array}{c}\text { R-PET Test } \\
\text { Sample }\end{array}$ & $\begin{array}{c}\text { V-PET Control } \\
\text { Sample }\end{array}$ \\
\hline Fibre composition & $\begin{array}{c}100 \% \text { recy- } \\
\text { cled polyester } \\
\text { (R-PET) }\end{array}$ & $\begin{array}{c}100 \% \text { virgin } \\
\text { polyester } \\
\text { (V-PET) }\end{array}$ \\
\hline Fabric structure & 1 x 1 Plain weave & $\begin{array}{c}1 \times 1 \text { Plain } \\
\text { weave }\end{array}$ \\
\hline $\begin{array}{c}\text { Fabric sett, No. of } \\
\text { yarns/cm }\end{array}$ & warp & 16 & 16 \\
\cline { 2 - 4 } & weft & 8 & 9 \\
\hline \multicolumn{2}{|c|}{ Yarn Linear density, dtex } & 1100 & 1100 \\
\hline \multicolumn{2}{|c|}{ No. of filaments in the yarn } & 210 & 192 \\
\hline \multicolumn{2}{|c|}{ Fabric weight, g/m ${ }^{2}$} & 315 & 300 \\
\hline
\end{tabular}

The physical mechanical properties of the developed R-PET fabric against V-PET fabric were tested. Before testing all samples were conditioned in a standard lab for 24 hours at $20 \pm 2^{\circ} \mathrm{C}$ and $65 \pm \%$ relative humidity.

\section{Dynamic tensile force - yarn strength}

The dynamic tensile strength, including the maximum force were tested using based on BS EN ISO 13934-1:2013. The Instron tensile tester Model 3345 was employed for this experiment. Samples with a dimension of $200 \times 50 \mathrm{~mm}$ were prepared and tested. 3 samples of both warp and weft were tested and average values were used. Figure 3 shows the test setup of the dynamic fabric tensile strength test, where fabric specimen is mounted between two fabric claps. The extension speed was set at $100 \mathrm{~mm} /$ min during the test.

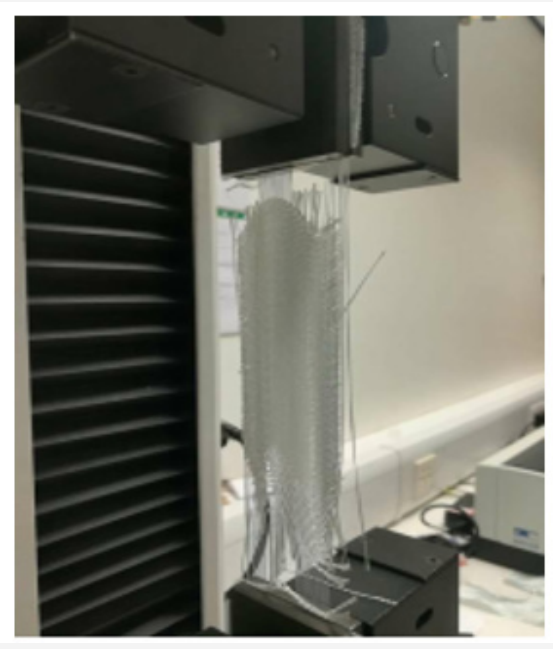

Figure 3: Experimental test setup of dynamic yarn strength test.
Abrasion resistance of the two fabrics R-PET and V-PET were tested according to standard BS EN ISO 12947 (1999). 795g of weights was used to place a $12 \mathrm{kPa}$ pressure load on the samples tested. Due to the fraying nature of the two fabrics, samples with a $39 \mathrm{~mm}$ radius circular were cut using a laser cutting machine FB Series.

2 samples of R-PET and 2 samples of V-PET were tested to 70,000 rubs/revolutions for yarn breakage and change in appearance assessment, according to standard BS EN ISO 129472:(2016). Photos were taken to document visible changes in pilling or fabric structure at each predetermined intervals and samples were inspected for yarn breakage. 2 samples of R-PET and 2 samples of V-PET were tested to 75,000 rubs/revolutions for yarn breakage and mass loss, according to standard BS EN ISO 12947-3:(1998). These samples were weighed before being placed on the Martindale tester. The mass of each sample was recorded at intervals specified for fabrics known to surpass 50,000 rubs/revolutions without yarn breakdown. Samples were inspected for yarn breakage and mass loss. The average value is used for comparison.

\section{Fabric assurance by simple testing methods}

The properties related to the tailorability of the R-PET and V-PET fabrics were tested using Fabric Assurance by Simple Testing (FAST) testing system. The compression properties of the two fabrics were tested using FAST -1 Compression Meter under the pressure of $196 \mathrm{~Pa}$ and 9.8 Pa respectively to obtain the surface and intrinsic thickness of the fabrics. 6 samples with a dimension of 100 x $50 \mathrm{~mm}$ were prepared for testing.

In FAST bending meter Bending Length $\mathrm{c}$ is defined based on the Bending Rigidity B which can be calculated by bending angle $\alpha$ shown in Figure 4. The fabric sample to be tested bends under its own weight until its leading edge intercepts a plane at an angle of $\alpha=41.5$ degrees from the horizontal. Bending Length was tested on the FAST - 2 Bending Meter. Samples were cut to $130 \times 50 \mathrm{~mm}$ with 5 in both warp and weft for each fabric. The resulting bending length ' $c$ ' was also combined with fabric weight or areal density ' $W$ ' ( $\mathrm{g} / \mathrm{m}^{2}$ ) to calculate bending rigidity 'B' (in $\mu \mathrm{N} . \mathrm{m}$ ) using Equations 1 and 2 .

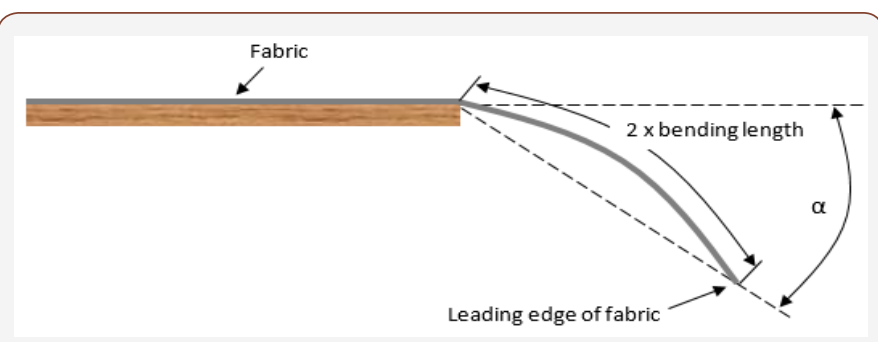

Figure 4: Bending measurement in FAST system.

$$
\begin{gathered}
c=\frac{l}{2} \\
B=W \times c^{3} \times 9.807 \times 10^{-6}
\end{gathered}
$$

The low stress tensile properties of the two fabrics were tested by FAST - 3 Extension Meter to determine the extension rate (\%) of 
the fabrics at loads of $5 \mathrm{gf} / \mathrm{cm}, 20 \mathrm{gf} / \mathrm{cm}$ and $100 \mathrm{gf} / \mathrm{cm}$ respectively, created by combinations of the weights provided with the tester. 5 samples with $130 \times 50 \mathrm{~mm}$ in dimension for both warp and weft of each fabric were tested. The results from this test were also combined with bending rigidity (calculated with the FAST-2 test) to determine fabric formability.

\section{Results and Discussion}

\section{Maximum force}

Figure 5 shows relative/normalized (at $1 \mathrm{~g} / \mathrm{m}^{2}$ basis for both fabrics) dynamic force needed to extend the R-PET fabric in warp direction in comparison to V-PET fabric, including the maximum force shown in the peaks of the two curves. The maximum force shows that R-PET is lower than V-PET fabric, but this difference is not significant. Considering the plain weave structure of both $\mathrm{R}$ and $\mathrm{V}$-PET fabrics it was assumed the maximum force in weft direction would present similarly. Figure 6 shows the average extension at breakage of the two types of fabrics. The extension for R-PET is higher than that of V-PET. This might be due to the lower amorphous/crystalline ratio in the R-PET fibre that makes it easier to be extended.

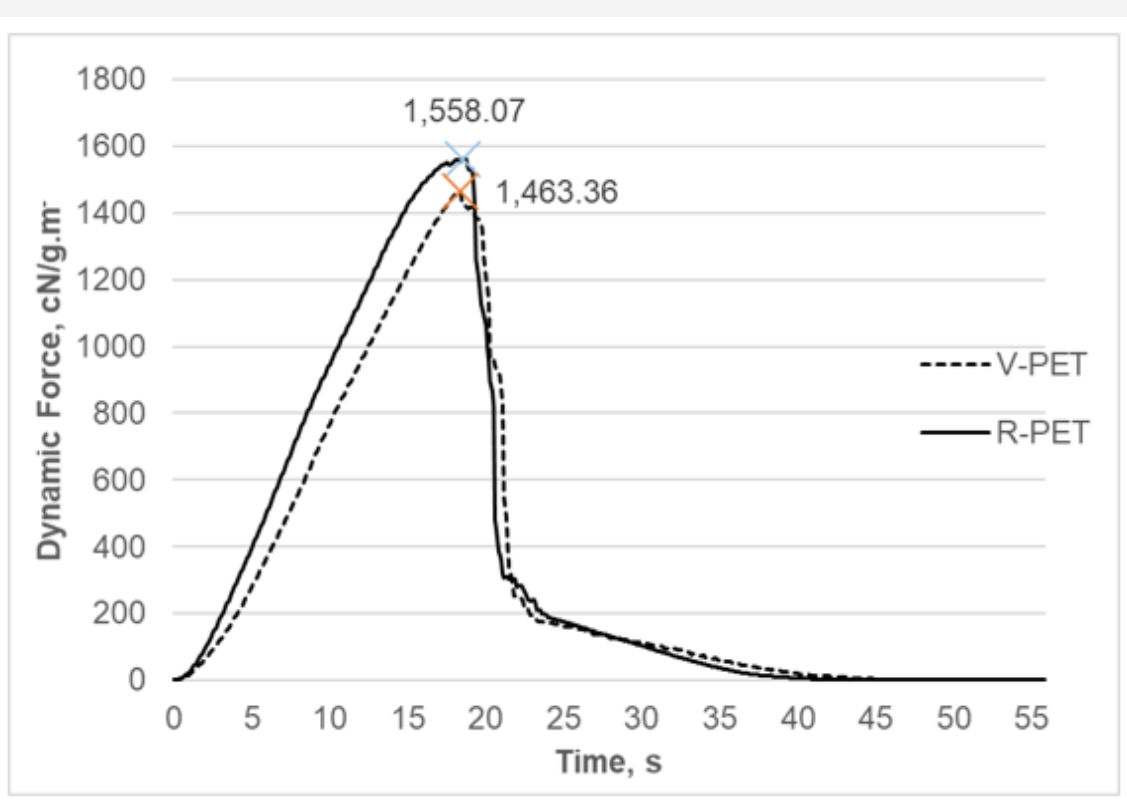

Figure 5: Relative dynamic force of R-PET and V-PET.

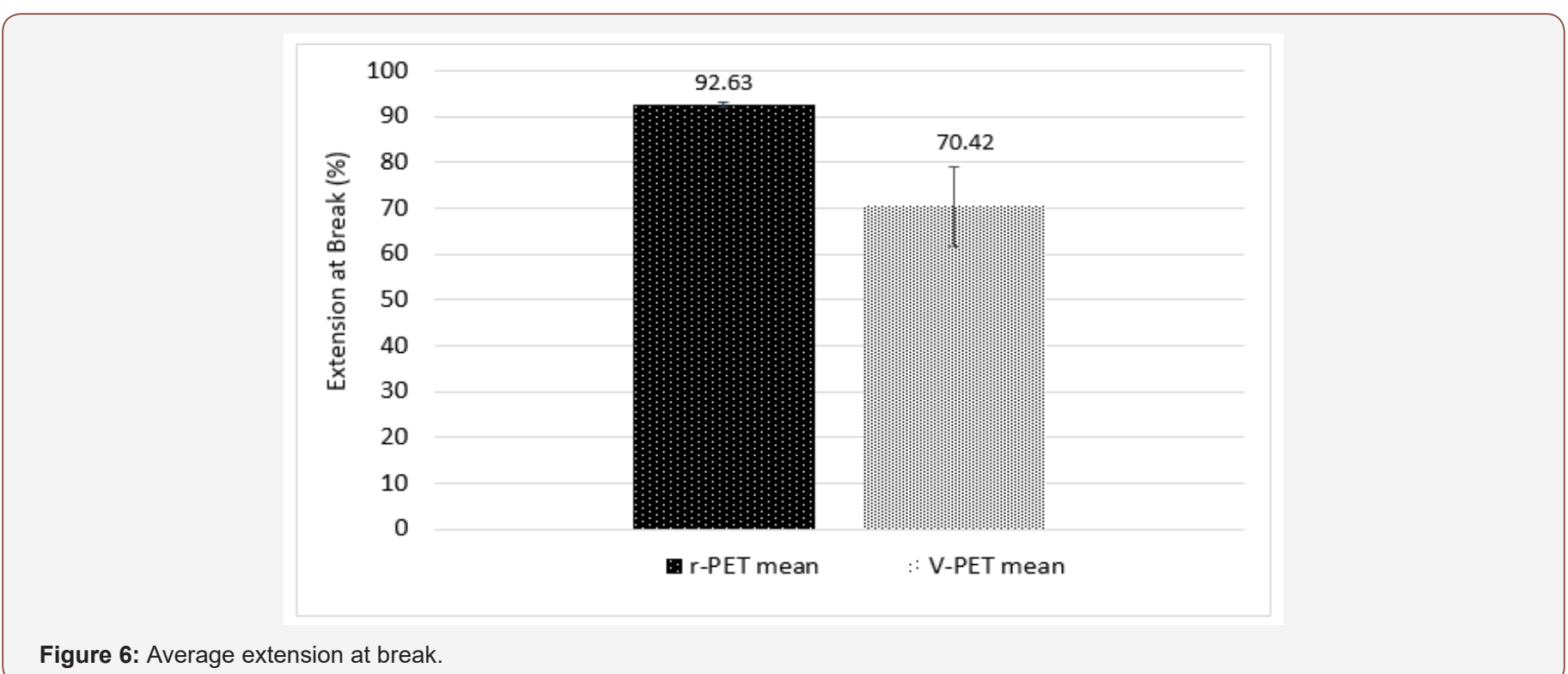

\section{Martindale abrasion results}

Table 2 documents the appearance change in fabric surface at significant intervals during the Matindale test. R-PET fabric shows earlier signs of pilling than that of V-PET fabric. However, it is noted at 50,000 rub intervals, the surface degradation began to slow down and the level between the tested and control fabrics. All samples passed the pre-determined limit of 70,000 rubs without any yarn breakage. Figure 7 shows the side view of surface effect of the two types of fabrics after being experienced from the abrasion resistance test. 
Table 2: Martindale abrasion test - appearance change and yarn breakage.

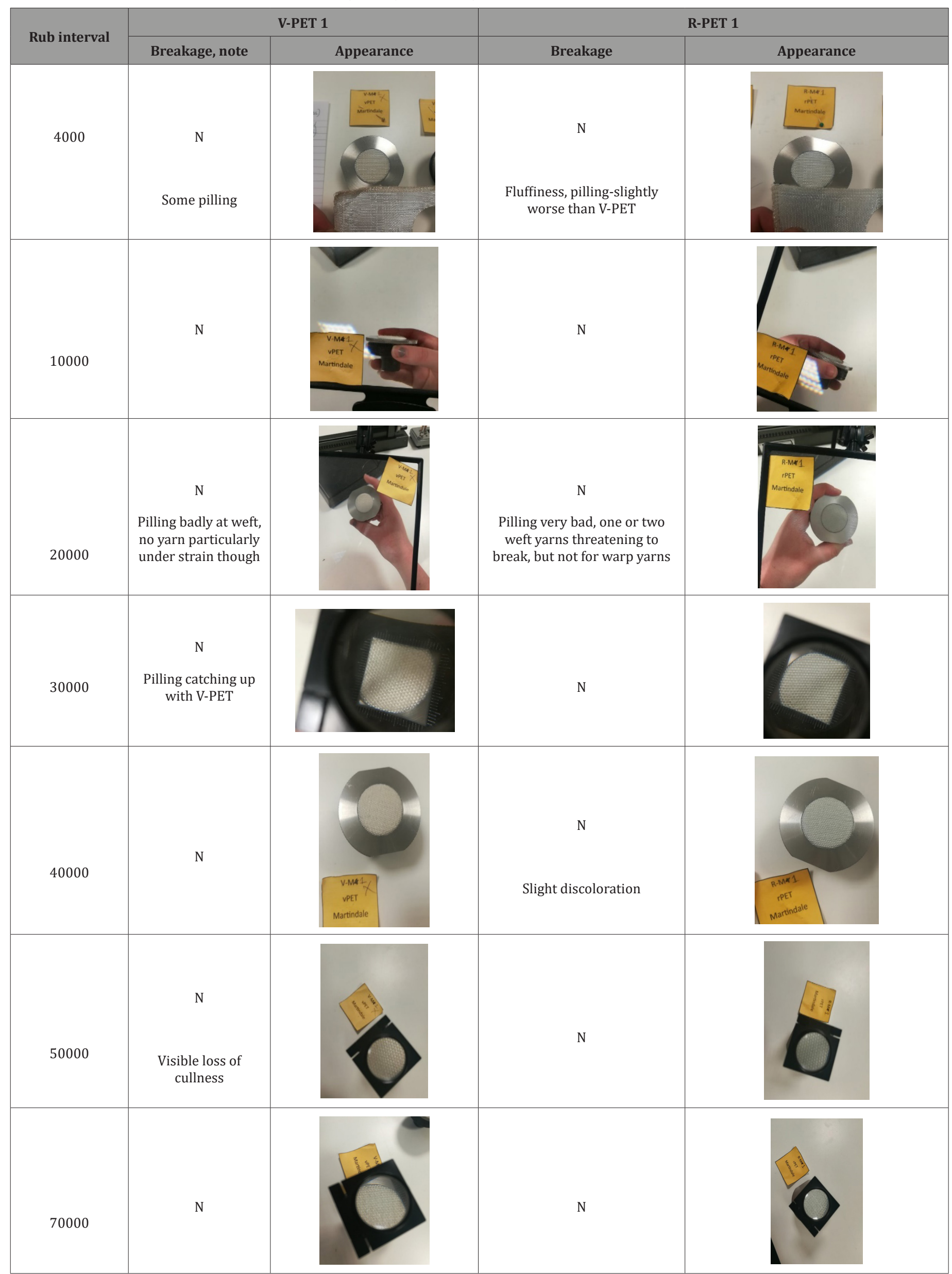




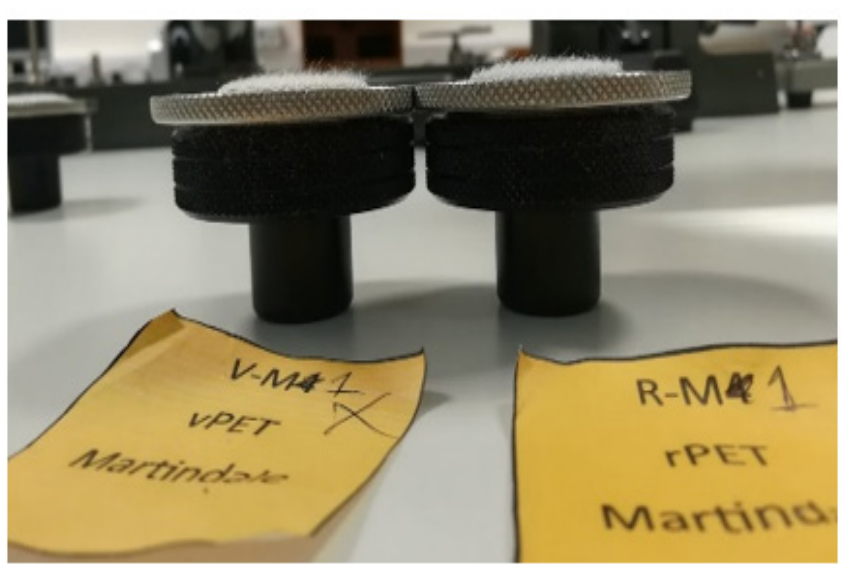

Figure 7: Side view of the V-PET and R-PET fabrics after abrasion resistance test.
Figure 8 presents the average cumulative mass loss/gain in fabrics R-PET and V-PET respectively. Results are displayed according to intervals as specified in the standard. All samples were tested with pass mark of 75,000 rubs without yarn breakage. Notably, both samples gained mass until the 25,000 intervals before losing mass, suggesting that the standard abradant fabric initially experienced more abrasion at the hand of the tested samples, and the tests accumulated off-cast fibres from the abradant. The abradant was changed, as is standard after 50,000 revolutions, and only after this point did the tested samples appear sustain an overall loss in mass. The standard error is slightly higher in the V-PET than in the R-PET, but given the very small range of increments, both fabrics performed on a closely comparable level, with V-PET maintaining a minutely higher resistance to the abrasion overall, with a more balanced curve and better retention of original mass.

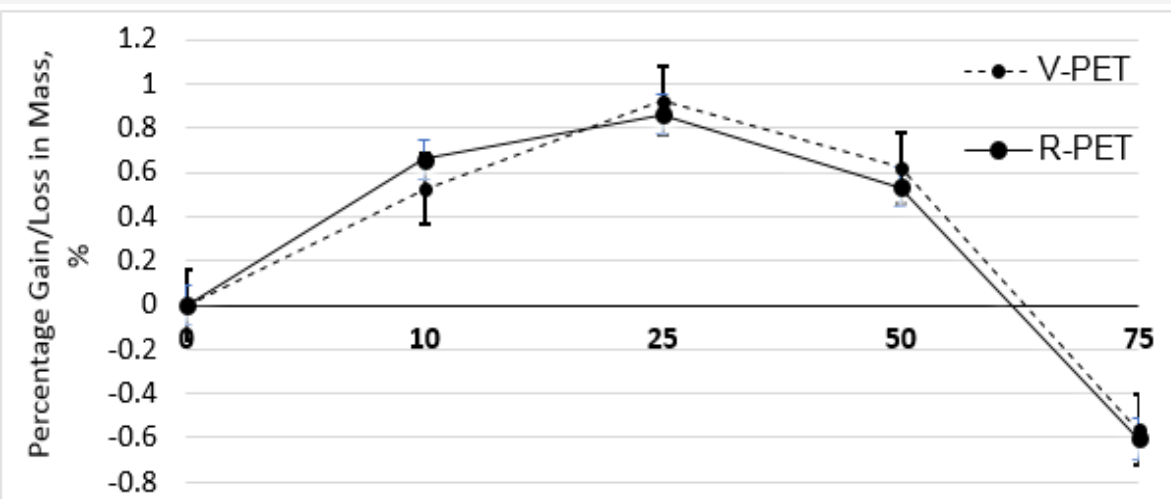

Abrasion revolutions, 1000 rubs

Figure 8: Martindale abrasion test - percentage mass loss/gain.

\section{FAST test - low stress physical mechanical properties}

The surface and intrinsic thickness of each fabric sample was calculated at $2 \mathrm{gf} / \mathrm{cm}^{2}$ and $100 \mathrm{gf} / \mathrm{cm}^{2}$ loads respectively. The difference between loads was expressed as percentage loss to demonstrate released or compressed surface thickness. R-PET incurred a relatively higher result, suggesting a higher level of compression to V-PET, and that V-PET better retained its structural integrity - but the difference is only a marginal of $0.12 \%$. The error bar does prompt some consideration, as the V-PET upper error margin exceeds that of R-PET. However, the V-PET average was taken as mean of only 4 samples. The results are show in Figure 9.

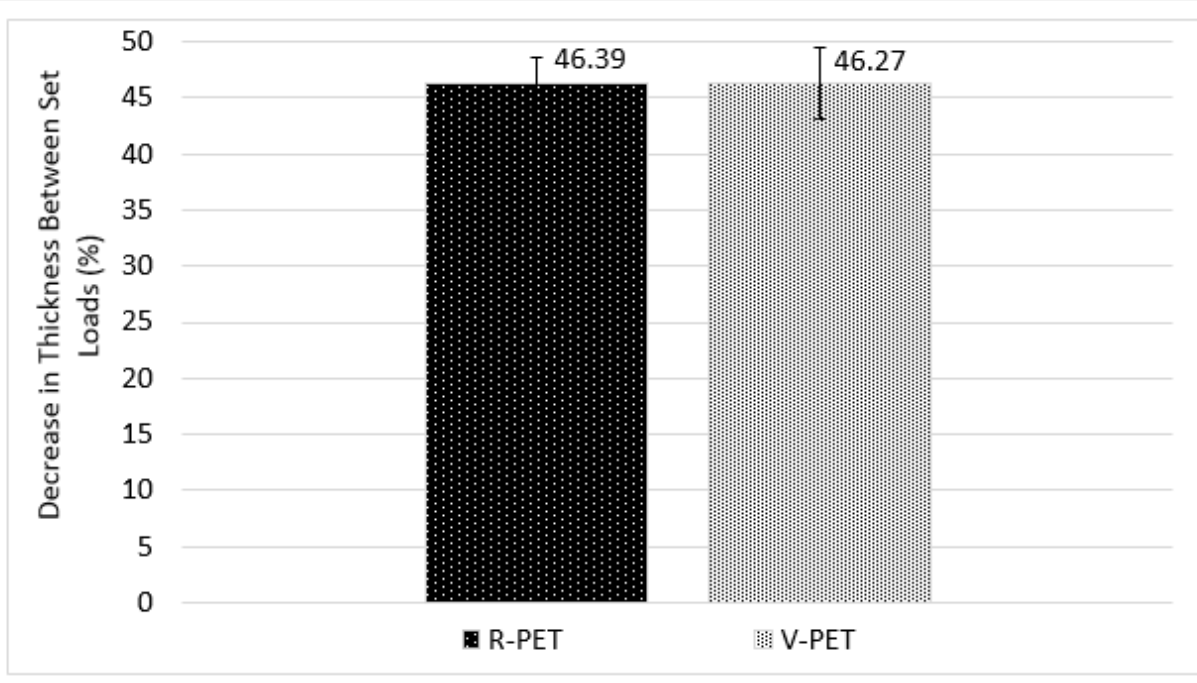

Figure 9: Released surface thickness. 
The bending length was calculated in warp and weft directions for R-PET and V-PET. The results were normalized as per $\mathrm{g} / \mathrm{m}^{2}$ basis, shown in Figure 10 to eliminate weight bias and converted and expressed as mean values with a unit of $\mu \mathrm{m} / \mathrm{g} \cdot \mathrm{m}^{-2}$. Both fabrics followed a similar trend in decreased bending length in the warp direction as compared to weft. Results are within a minute range in the context of the parameters and error margins prove reliable.

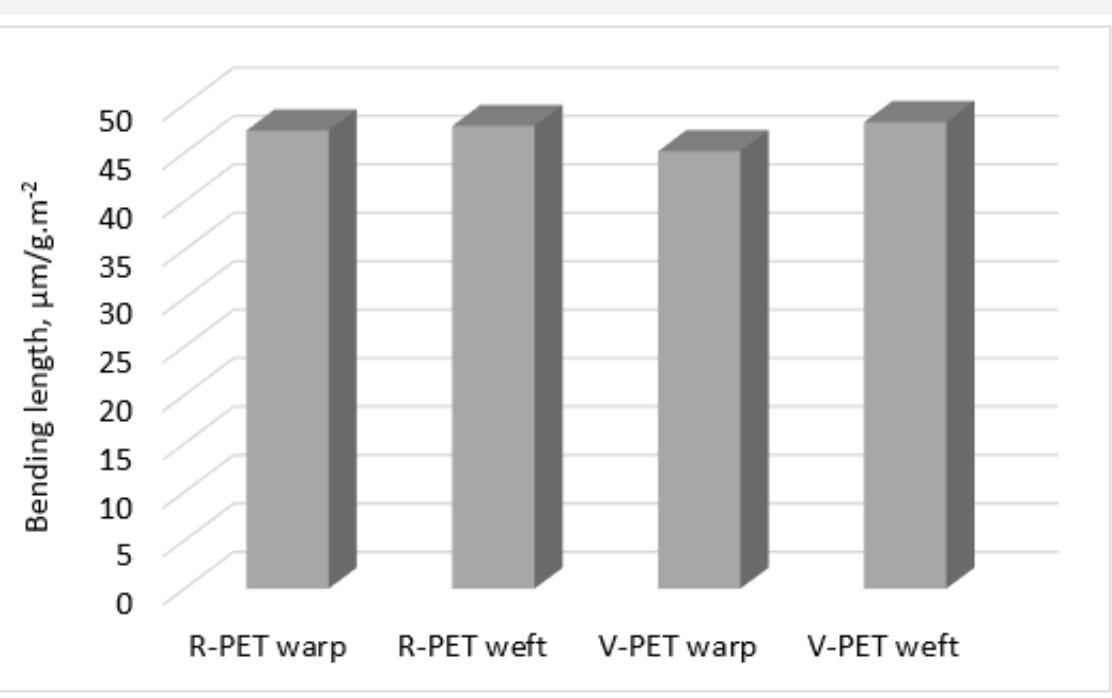

Figure 10: Bending length based on normalized fabric weight.

Bending rigidity was calculated from raw bending length results and individual fabric weight using equation 1 and 2. R-PET showed in Figure 11, a strong trend towards higher bending rigidity than V-PET, suggesting more stiffness.

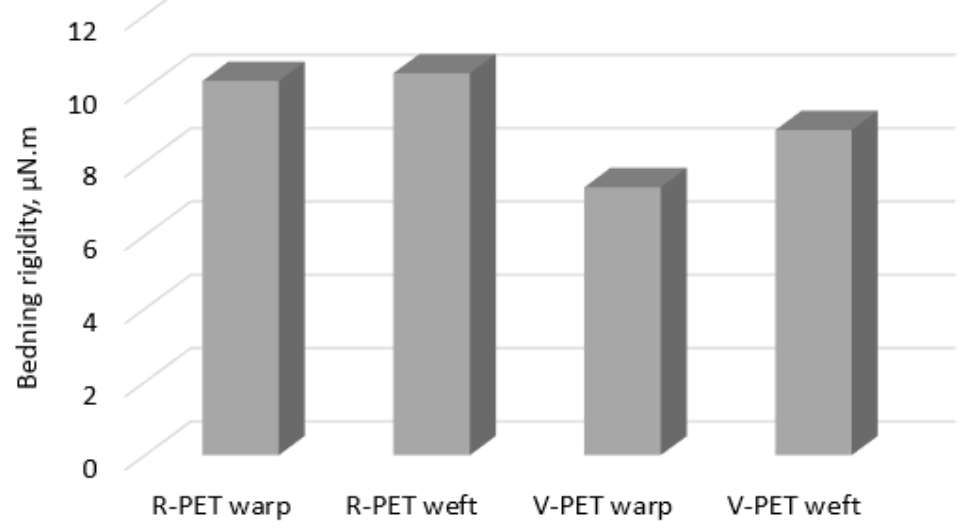

Figure 11: Bending rigidity of R-PET and V-PET fabrics.

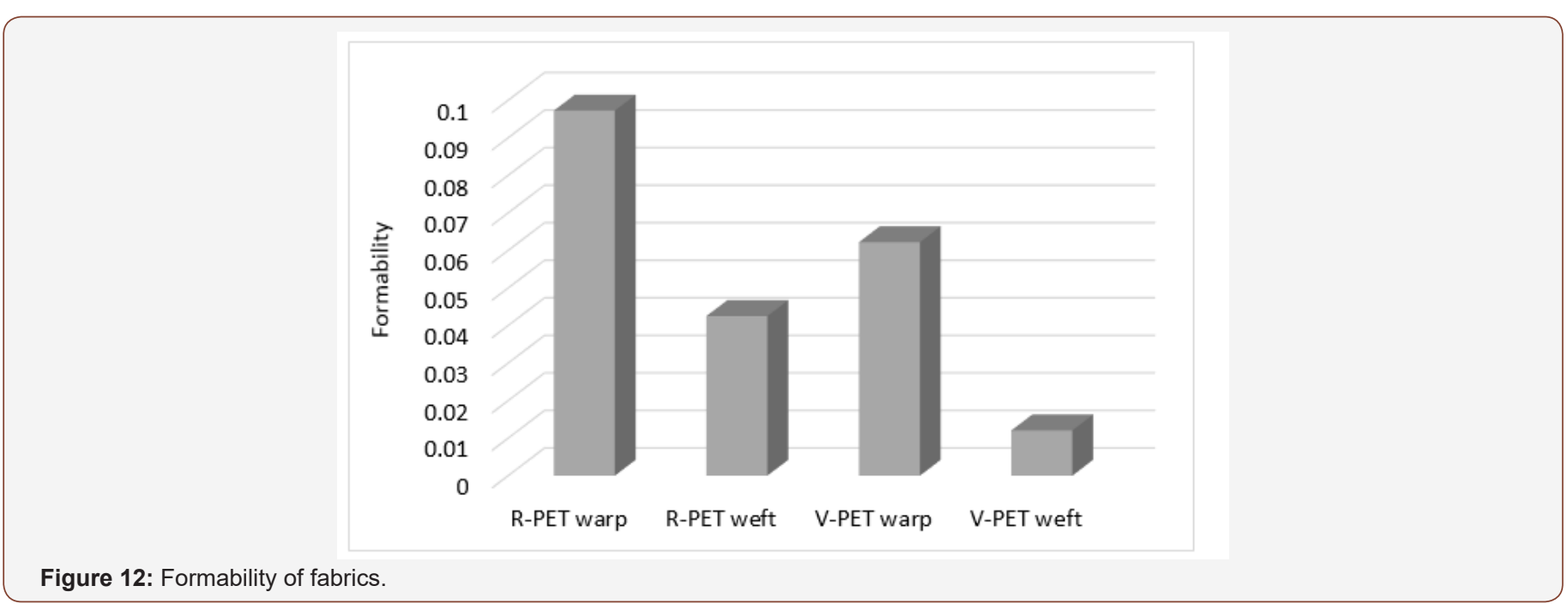


Formability ( $\mathrm{F}$, in $\mathrm{mm}^{2}$ ), was calculated using Bending Rigidity and Extension property of the fabrics using Equation 3. As with the former, weight bias was intrinsically eliminated through the equation. R-PET displayed markedly higher results in both directions as shown in Figure 12, suggesting an increased ease of use during garment construction.

$$
F=\frac{\left(E_{20}-E_{5}\right) \times B}{14.7}
$$

where, $E_{20}$ and $E_{5}$ are extension at $20 \mathrm{gf} / \mathrm{cm}$ and $5 \mathrm{gf} / \mathrm{cm}$ respectively, in \%; and $\mathrm{B}$ is bending rigidity, in $\mu$ N.m.

One minor limitation is that the virgin polyester yarn used is dyed/colored, which may have slightly impact to the yarn strength and other properties examined in this study. The resulting difference in quality was off-set with comparison of the normalized weight (R-PET is 5\% heavier than V-PET) to successfully eliminate weight influence of the resulting results.

\section{Conclusion}

The property differences between R-PET and V-PET are not significant. The findings from this study is very positive especially the maximum breaking force which was expected to underperform. It can be concluded that R-PET has the potential to perform on a comparative level to V-PET.

The key disadvantage of R-PET for use in apparel is its rigidity based on this study. However, performance value is not limited to apparel. Rigidity, however, may be a specified beneficial characteristic in other end use application. The R-PET developed from this work could potentially serve as material for ocean waste collection bags, aided by its rigid structure in withstanding extreme conditions of wind and water.

It is recommended that for companies to be confident in using R-PET into their brand product production, other properties of R-PET that are important related to the end use requirements such as dyeability, color fastness against washing, UV light, properties related to wear comfort such as air permeability, water vapor permeability etc. will need to be investigated.

\section{Acknowledgement}

None.

\section{Conflict of Interest}

No conflict of interest.

\section{References}

1. Hardesty BD, Wilcox C (2017) Eight million tonnes of plastic are going into the ocean each year. The Conversation.

2. (2017) Parley, Parley for the oceans.

3. (2019) Mintel Market Sizes, Bottled Water - UK.

4. Sinha V, Patel MR, Patel JV (2010) PET waste management by chemical recycling: A review. J Polym Environ 18(1): 8-25.

5. (2016) Textile Exchange, Preferred fiber market report s.l.: Textile Exchange.

6. Laville S, Yaylor M (2017) A million bottles a minute: world's plastic binge 'as dangerous as climate change. The Guardian.

7. Salem AL, Lettieri SM, Baeyens P (2009) Recycling and recovery routes of plastic waste (PSW): A review. Waste Management 29(10): 26252643.

8. Ikenaga K, Inoue T, Kusakabe K (2016) Hydrolysis of PET by combining direct microwave heating with high pressure. Procedia Engineering 148: 314-318.

9. Al-Sabagh AM, Yehia FZ, Eshaq Gh, Rabie AM, El-Metwally AE (2016) Greener routes for recycling of polyethylene terephthalate. Egyptian Journal of Petroleum 25(1): 53-64.

10. Awaji A, Pavel D (2005) Recycling of PET. European polymer journal 41(7): 1453-1477.

11. Naguib HM, Zhang XH (2018) Advanced recycled polyester based on PET and oleic acid. Polymer testing 69: 450-455.

12. Shen L, Worrell E, Patel MK (2010) Open-loop recycling: A LCA case study of PET bottle-to fibre recycling. Resources, Conservation and Recycling 55(1): 34-52.

13. Eco Circle ${ }^{\mathrm{TM}}$ Fibers. TEJIN.

14. Makkam S, Harnnarongchai W (2014) Rheological and mechanical properties of recycled PET modified by reactive extrusion, Energy Procedia 56: 547-553. 